\title{
Sepsis, Coagulation, and Antithrombin: Old Lessons and New Insights
}

\author{
Marcel Levi, M.D., Ph.D., F.R.C.P.', ${ }^{1}$ Marcel Schouten, M.D., ${ }^{1,2,3}$ \\ and Tom van der Poll, M.D., Ph.D. ${ }^{1,2,3}$
}

\section{ABSTRACT}

Current insights in the pathogenesis of multiple organ dysfunction in patients with sepsis point to a pivotal role of inflammation and coagulation. One of the most important mechanisms contributing to the activation of coagulation in sepsis is the downregulation of physiologic anticoagulant systems, such as the antithrombin pathway. More than 20 years ago, Eberhard Mammen already hypothesized that coagulation activation and antithrombin were important factors in patients with sepsis. Abundant experimental and clinical studies have supported that notion in recent years. The better understanding of the pathogenesis of coagulation activation and the role of natural anticoagulants in sepsis has led to the development of anticoagulant factor concentrates, such as antithrombin concentrate. Clinical studies indicate that these interventions may have a role in the (supportive) treatment of patients with sepsis, mostly based on surrogate outcomes, but ongoing studies will have to confirm a beneficial effect in reducing mortality.

KEYWORDS: Sepsis, coagulation, thrombosis, antithrombin

$I_{t}$ has been known for decades that many patients with sepsis present with coagulation abnormalities; however, in the previous century, the clinical relevance of these findings was not always clear and generated some debate in the literature. ${ }^{1}$ Eberhard Mammen was one of the first authors to recognize the central role of hemostatic changes in patients with severe infection and sepsis and summarized these thoughts in a series of comprehensive review articles. ${ }^{2,3} \mathrm{He}$ argued that not only in its most extreme form (i.e., disseminated intravascular coagulation $[\mathrm{DIC}])$, but also in more subclinical manifestations, coagulation could play an important role in the pathogenesis of organ dysfunction in patients with sepsis. Indeed, recent findings confirm these hypothetical thoughts of Eberhard Mammen. ${ }^{4-6}$ There are several lines of evidence confirming that activation of coagulation in concert with inflammatory activation can result in microvascular thrombosis and thereby contribute to multiple organ failure in patients with severe sepsis. ${ }^{7}$ First, extensive data has been reported on postmortem findings of patients with coagulation abnormalities and DIC in patients with severe infectious diseases. ${ }^{8,9}$ Importantly, the presence of these intravascular thrombi seems to be clearly and specifically related to the clinical dysfunction of the organ. Second, experimental animal studies of DIC show fibrin deposition in various organs. Experimental bacteremia or endotoxemia causes intravascular and extravascular fibrin deposition in kidneys, lungs, liver, brain, and various other organs. Amelioration of the hemostatic defect by various interventions in these experimental models appears to improve organ function (i.e., reduce organ failure) and,
${ }^{1}$ Department of Medicine, and ${ }^{2}$ Laboratory of Experimental Internal Medicine, ${ }^{3}$ Center for Infection and Inflammation Research (CINIMA), Academic Medical Center, University of Amsterdam, Amsterdam, The Netherlands.

Address for correspondence and reprint requests: Marcel Levi, M.D., Ph.D., F.R.C.P., Department of Medicine (F-4), Academic Medical Center, University of Amsterdam, Meibergdreef 9, 1105 AZ
Amsterdam, The Netherlands (e-mail: m.m.levi@amc.uva.nl).

A Tribute to Eberhard F. Mammen, M.D. (1930-2008); Guest Editor, Emmanuel J. Favaloro, Ph.D., M.A.I.M.S.

Semin Thromb Hemost 2008;34:742-746. Copyright (C) 2008 by Thieme Medical Publishers, Inc., 333 Seventh Avenue, New York, NY 10001, USA. Tel: +1(212) 584-4662.

DOI 10.1055/s-0029-1145256. ISSN 0094-6176. 
in some but not all cases, improve mortality. ${ }^{10-13}$ Interestingly, some studies indicate that amelioration of the systemic coagulation activation will have a profound beneficial effect on resolution of local fibrin deposition and improvement of organ function/reduction in failure. $^{14,15}$ Lastly, clinical studies support the notion of coagulation as an important denominator of clinical outcome. DIC has shown to be an independent predictor of organ failure and mortality in patients with sepsis. ${ }^{16,17}$

\section{ANTICOAGULANT FACTORS IN SEPSIS}

In general, activation of coagulation is regulated by three major anticoagulant pathways: antithrombin, the protein C system, and tissue factor pathway inhibitor. ${ }^{18,19}$ During sepsis-induced activation of coagulation, the function of all three pathways can be impaired. The protein $\mathrm{C}$ pathway has attracted a lot of attention in recent years, not only because the central role of this system in modulating both coagulation and inflammation in sepsis has been demonstrated, but also because restoration of this pathway, by administration of recombinant human activated protein $\mathrm{C}$, was shown to be beneficial in patients with severe sepsis. Also, animal experiments of severe inflammation-induced coagulation activation convincingly show that compromising the protein $\mathrm{C}$ system results in increased morbidity and mortality, whereas restoring an adequate function of activated protein $\mathrm{C}$ improves survival and reduces organ failure. $^{20,21}$ Interestingly, mice with a one-allele targeted deletion of the protein $\mathrm{C}$ gene (resulting in heterozygous protein $\mathrm{C}$ deficiency) have more severe DIC and organ dysfunction and a higher mortality than do wild-type littermates. $^{22}$

However, more than 25 years ago, antithrombin was also recognized as an important regulator of coagulation, and possibly also inflammation, in patients with sepsis. Eberhard Mammen was one of the first who identified the importance of this coagulation inhibitor and the potential for antithrombin replacement in patients with severe sepsis. ${ }^{23-25}$ Although at present the ultimate proof that antithrombin concentrate in patients with sepsis will reduce mortality has still to come, there is quite some evidence for a potentially beneficial effect of this treatment strategy.

\section{ROLE OF ANTITHROMBIN IN COAGULATION AND INFLAMMATION ACTIVATION IN SEPSIS}

Antithrombin predominately inhibits factor $\mathrm{Xa}$ and thrombin and also has inhibitory properties toward tissue factor-factor VIIa (TF-FVIIa) and FIXa. The anticoagulant properties of antithrombin have been shown extensively in vivo. ${ }^{26}$ For example, treatment with antithrombin improved survival, concurrently in- hibiting the procoagulant response and hyperinflammation during severe sepsis in the baboon. ${ }^{27,28}$ Most notably, infusion of antithrombin dose-dependently reduced TF-triggered coagulation and, moreover, ameliorated IL-6 production in a human model of endotoxemia. ${ }^{29}$ Apart from its anticoagulant activities, antithrombin has been described to possess direct antiinflammatory activity. For example, on human umbilical vein endothelial cells, antithrombin increased prostacyclin formation, and administration of heparin abolished this effect. ${ }^{30}$ Indeed, antithrombin decreased ischemiareperfusion injury in the rat liver by increasing the hepatic lever of prostacyclin ${ }^{31}$ and also in another model of ischemia-reperfusion in a prostacyclin-dependent manner. ${ }^{32}$ Moreover, antithrombin reduces leukocyte rolling on the endothelium. ${ }^{33}$ In sepsis, plasma levels of antithrombin are markedly decreased due to a combination of an impaired synthesis as a result of a negative acute-phase response and impaired liver function, degradation by elastase from activated neutrophils, and, importantly, consumption as a result of ongoing thrombin generation. ${ }^{34}$ The anticoagulant activities of antithrombin are normally accelerated, to a large extent, by heparin-like glycosaminoglycans (GAGs), such as heparan sulfate (HS), that are abundantly present on the endothelial surface in the glycocalyx. Proinflammatory cytokines, such as tumor necrosis factor- $\alpha$, degrade the glycocalyx and reduce the synthesis of GAGs on the endothelial surface, which contributes to reduced antithrombin function in sepsis. ${ }^{35}$ It was shown recently that specific disruption of the glycocalyx results in thrombin generation and platelet adhesion within a few minutes. ${ }^{36}$ Moreover, loss of glycocalyx in vivo has been associated with subendothelial edema formation. ${ }^{37}$ It seems conceivable that the glycocalyx is disturbed in sepsis also, although evidence for this is still preliminary. The role of the glycocalyx in modulating endothelial function, including anticoagulation, and the role of the endothelium in modulating the glycocalyx in sepsis surely need further research.

\section{CLINICAL TRIALS OF ANTITHROMBIN CONCENTRATE IN SEPSIS}

Antithrombin replacement therapy in patients with severe sepsis and DIC has been used since the 1980s. The rationale for this adjunctive treatment strategy is based on the notion that natural anticoagulant pathways are defective in patients with a severe systemic inflammatory response upon infection, and this may play a central role in the systemic generation of thrombin and subsequent formation of microthrombi, which may in turn contribute to the pathogenesis of organ dysfunction. $^{38,39}$ Indeed, plasma levels of antithrombin are (very) low in patients with sepsis and are independent predictors of the clinical outcome. ${ }^{17,40} \mathrm{~A}$ substantial 
drop in the level of circulating antithrombin has been demonstrated to be a very early phenomenon in sepsis, lending support to the idea that this protease inhibitor is involved in the pathogenesis of the disease. In addition, experimental studies suggest that antithrombin may not only have anticoagulant properties but also may modulate inflammatory responses. ${ }^{27}$ Previous studies have shown that the strong interaction between coagulation and inflammation may indeed be a suitable pointof-impact of new adjunctive strategies in patients with severe sepsis. ${ }^{5,41}$ Antithrombin concentrate has been evaluated in several small clinical trials. All trials show some beneficial effect in terms of improvement of a DIC score, shortening of the duration of DIC, or even improvement in organ function. Because all trials, however, used highly variable criteria for assessing these outcomes, it is hard to compare results with one another. In the more recent clinical trials, very high doses of antithrombin concentrate to attain supraphysiologic plasma levels were used, and the beneficial results in these trials seem to be more distinct. Some trials showed a modest reduction in mortality in antithrombin-treated patients; however, the effect never reached statistical significance. Aggregate results suggested at least a trend toward a reduction in mortality from 47 to $32 \%$ (odds ratio, $0.59 ; 95 \%$ confidence interval, 0.39 to 0.87$).{ }^{42} \mathrm{~A}$ large, randomized, controlled clinical trial in 2314 patients with severe sepsis (Kybersept trial), however, did not demonstrate a difference between treatment with antithrombin for 4 days versus placebo. ${ }^{43}$ Interestingly, the subgroup of patients that did not receive concomitant heparin (which was at the discretion of the attending physician) had a clear trend toward a better survival at 28 days, which was statistically significant at 90 days. Apparently, the combination of antithrombin concentrate and administration of heparin does not work out very well. Interestingly, this conclusion was already suggested in the very first clinical trials of antithrombin in patients with DIC 25 years ago but may have been forgotten over time. ${ }^{44}$

\section{THE COMBINATION OF ANTITHROMBIN CONCENTRATE AND HEPARIN}

The fact that intravenous infusion of antithrombin did not alter mortality in patients with sepsis may possibly be due to the fact that the antithrombin effect may have been obscured by concurrent heparin treatment, considering that heparin, which is a highly sulfated version of heparan sulfate, has been found, like other soluble GAGs, to antagonize the anti-inflammatory and microcirculatory effects of antithrombin. ${ }^{30}$ Heparin sulfate polysaccharides are ubiquitously expressed as heparan sulfate proteoglycans (HSPGs) on cell surfaces such as the endothelium. Direct binding of bacteria to HSPGs on alveolar epithelium has been described; however, this phenomenon has not been reported for HSPGs on endothelium, nor has this finding been substantiated in vivo. ${ }^{45}$ GAGs have been shown to interfere with antibacterial properties of the antimicrobial cathelicidin LL-37. The same phenomenon could play a role with heparin. ${ }^{46}$ GAGs have been described to be able to play an important proinflammatory role by participating in almost every stage of leukocyte transmigration through the vessel wall. This holds true especially for HSPGs. Endothelial HSPGs facilitate adhesion of leukocytes to the inflamed endothelium by binding to L-selectin expressed by leukocytes. HSPGs also play a role in endothelial transcytosis and subsequent presentation of chemokines such as IL-8, which is important for leukocyte activation and subsequent production of integrins that tighten leukocyte binding to the endothelium. ${ }^{47}$ Moreover, HSPGs facilitate leukocyte transmigration through the vessel wall, possibly by binding proteins that regulate vascular permeability, such as kininogen. ${ }^{48}$ To cross the endothelial basement membrane, leukocytes secrete various proteases such as heparanase, which releases growth factors that are normally associated with basement membrane HSPGs. These growth factors play a role in the establishment of an acute and chronic inflammatory reaction by modulating angiogenesis and tissue remodeling. ${ }^{47}$

HS polysaccharide structure can vary substantially by different positioning of sulfate groups and by epimerization of glucuronic acid residues to iduronic acid. Together with varying negative-charge densities, this provides for much structural heterogeneity. Binding of different HSPGs to different proteins can affect their biological properties; for example, in growth hormone and chemokine signaling. ${ }^{48,49}$ Although the synthesis of GAGs has been described to be reduced by proinflammatory cytokines, HSPGs specifically can be upregulated in inflammatory conditions. ${ }^{48}$ That implies they could play an important proinflammatory role in sepsis. Exogenous heparin, however, could have an anti-inflammatory effect by interfering in the interaction between leukocytes and (sub)endothelial HSPGs, for example, by binding to $\mathrm{P}$ - and L-selectin. ${ }^{50}$

\section{THE IMPORTANCE OF THE ANTICOAGULANT EFFECT OF ANTITHROMBIN IN SEPSIS}

A recent paper showed that shortly after the administration of antithrombin to patients with severe sepsis, D-dimer levels sharply decreased. ${ }^{51}$ It should be remembered that in the phase II dose-finding study of recombinant human activated protein $\mathrm{C}$ in patients with severe sepsis that preceded the successful placebo-controlled trial showing a survival benefit of this treatment, the dose of activated protein $\mathrm{C}$ was based on the reduction in 
D-dimer levels. ${ }^{52}$ In addition, recent analyses of the Kybersept database reveal that the presence of DIC is a strong predictor of a beneficial effect of antithrombin. In fact, patients that did not receive heparin and that had a positive DIC score (according to the international scoring system $)^{53}$ had a relative risk reduction for death of $~ 30 \%$, whereas patients that did not have DIC had no treatment benefit. This finding is reminiscent of data from the phase III Prowess trial of recombinant human activated protein $\mathrm{C}$ in patients with severe sepsis, showing that patients with DIC had a relatively larger reduction in mortality than did patients without DIC. ${ }^{54}$ This may indicate that for selected patients with severe sepsis, administration of antithrombin concentrate may be beneficial. This hypothesis, however, needs prospective confirmation in a properly designed, randomized, controlled clinical trial, which is currently under way. The odds of finding a successful result by administering antithrombin to patients with severe sepsis in such a trial may be greatly improved by the recent insights mentioned above and would evidently have a potentially major impact on the treatment of patients with severe sepsis.

\section{CONCLUSION}

The importance of coagulation in the pathogenesis of sepsis and the relative contribution of impaired anticoagulant pathways, in particular the antithrombin system, was highlighted by Eberhard Mammen's work well before these concepts became mainstream insights. ${ }^{2,25} \mathrm{It}$ is interesting to see how quickly this improvement in the understanding in sepsis pathogenesis is translated into new treatment options for patients with a deranged coagulation system as a consequence of severe sepsis. ${ }^{39}$ Many of these treatment modalities are currently being evaluated in clinical trials and will hopefully ultimately contribute to a better outcome of patients with severe sepsis.

\section{REFERENCES}

1. Strieter RM, Lynch JP III, Basha MA, Standiford TJ, Kasahara K, Kunkel SL. Host responses in mediating sepsis and adult respiratory distress syndrome. Semin Respir Infect 1990;5:233-247

2. Mammen EF. The haematological manifestations of sepsis. J Antimicrob Chemother 1998;41(Suppl A):17-24

3. Mammen EF. Disseminated intravascular coagulation (DIC). Clin Lab Sci 2000;13:239-245

4. Wheeler AP, Bernard GR. Treating patients with severe sepsis. N Engl J Med 1999;340:207-214

5. Levi M, van der Poll T, Buller HR. Bidirectional relation between inflammation and coagulation. Circulation 2004;109: 2698-2704

6. Levi M. Disseminated intravascular coagulation. Crit Care Med 2007;35:2191-2195
7. Levi M, Keller TT, van Gorp E, ten Cate H. Infection and inflammation and the coagulation system. Cardiovasc Res 2003;60:26-39

8. Robboy SJ, Major MC, Colman RW, Minna JD. Pathology of disseminated intravascular coagulation (DIC). Analysis of 26 cases. Hum Pathol 1972;3:327-343

9. Shimamura K, Oka K, Nakazawa M, Kojima M. Distribution patterns of microthrombi in disseminated intravascular coagulation. Arch Pathol Lab Med 1983;107:543-547

10. Creasey AA, Chang AC, Feigen L, Wun TC, Taylor FBJ, Hinshaw LB. Tissue factor pathway inhibitor reduces mortality from Escherichia coli septic shock. J Clin Invest 1993;91:2850-2856

11. Kessler CM, Tang Z, Jacobs HM, Szymanski LM. The suprapharmacologic dosing of antithrombin concentrate for Staphylococcus aureus-induced disseminated intravascular coagulation in guinea pigs: substantial reduction in mortality and morbidity. Blood 1997;89:4393-4401

12. Taylor FBJ, Chang A, Ruf W, et al. Lethal E. coli septic shock is prevented by blocking tissue factor with monoclonal antibody. Circ Shock 1991;33:127-134

13. Taylor FBJ, Chang A, Esmon CT, D'Angelo A, ViganoD'Angelo S, Blick KE. Protein C prevents the coagulopathic and lethal effects of Escherichia coli infusion in the baboon. J Clin Invest 1987;79:918-925

14. Welty-Wolf KE, Carraway MS, Miller DL, et al. Coagulation blockade prevents sepsis-induced respiratory and renal failure in baboons. Am J Respir Crit Care Med 2001;164: 1988-1996

15. Miller DL, Welty-Wolf K, Carraway MS, et al. Extrinsic coagulation blockade attenuates lung injury and proinflammatory cytokine release after intratracheal lipopolysaccharide. Am J Respir Cell Mol Biol 2002;26:650-658

16. Levi M, ten Cate H. Disseminated intravascular coagulation. N Engl J Med 1999;341:586-592

17. Fourrier F, Chopin C, Goudemand J, et al. Septic shock, multiple organ failure, and disseminated intravascular coagulation. Compared patterns of antithrombin III, protein C, and protein S deficiencies. Chest 1992;101:816-823

18. Levi M, van der Poll T. The role of natural anticoagulants in the pathogenesis and management of systemic activation of coagulation and inflammation in critically ill patients. Semin Thromb Hemost 2008;34:459-468

19. Laterre PF, Wittebole X, Collienne C. Pharmacological inhibition of tissue factor. Semin Thromb Hemost 2006; 32: 71-76

20. Taylor FBJ, Dahlback B, Chang AC, et al. Role of free protein $\mathrm{S}$ and $\mathrm{C} 4 \mathrm{~b}$ binding protein in regulating the coagulant response to Escherichia coli. Blood 1995;86:2642-2652

21. Esmon CT. Inflammation and the activated protein $\mathrm{C}$ anticoagulant pathway. Semin Thromb Hemost 2006; 32(Suppl 1):49-60

22. Levi M, Dorffler-Melly J, Reitsma PH, et al. Aggravation of endotoxin-induced disseminated intravascular coagulation and cytokine activation in heterozygous protein $\mathrm{C}$ deficient mice. Blood 2003;101:4823-4827

23. Mammen EF. Antithrombin III and sepsis. Intensive Care Med 1998;24:649-650

24. Balk R, Emerson T, Fourrier F, et al. Therapeutic use of antithrombin concentrate in sepsis. Semin Thromb Hemost 1998;24:183-194

25. Mammen EF. Antithrombin: its physiological importance and role in DIC. Semin Thromb Hemost 1998;24:19-25 
26. Dickneite G. Antithrombin III in animal models of sepsis and organ failure. Semin Thromb Hemost 1998;24:61-69

27. Minnema MC, Chang AC, Jansen PM, et al. Recombinant human antithrombin III improves survival and attenuates inflammatory responses in baboons lethally challenged with Escherichia coli. Blood 2000;95:1117-1123

28. Taylor FBJ, Emerson TEJ, Jordan R, Chang AK, Blick KE. Antithrombin-III prevents the lethal effects of Escherichia coli infusion in baboons. Circ Shock 1988;26:227-235

29. Leitner JM, Firbas C, Mayr FB, Reiter RA, Steinlechner B, Jilma B. Recombinant human antithrombin inhibits thrombin formation and interleukin 6 release in human endotoxemia. Clin Pharmacol Ther 2006;79:23-34

30. Horie S, Ishii H, Kazama M. Heparin-like glycosaminoglycan is a receptor for antithrombin III-dependent but not for thrombin-dependent prostacyclin production in human endothelial cells. Thromb Res 1990;59:895-904

31. Harada N, Okajima K, Kushimoto S, Isobe H, Tanaka K. Antithrombin reduces ischemia/reperfusion injury of rat liver by increasing the hepatic level of prostacyclin. Blood 1999; 93:157-164

32. Mizutani A, Okajima K, Uchiba M, et al. Antithrombin reduces ischemia/reperfusion-induced renal injury in rats by inhibiting leukocyte activation through promotion of prostacyclin production. Blood 2003;101:3029-3036

33. Ostrovsky L, Woodman RC, Payne D, Teoh D, Kubes P. Antithrombin III prevents and rapidly reverses leukocyte recruitment in ischemia/reperfusion. Circulation 1997;96: 2302-2310

34. Levi M, van der Poll T. Two-way interactions between inflammation and coagulation. Trends Cardiovasc Med 2005; 15:254-259

35. Nieuwdorp M, Meuwese MC, Mooij HL, et al. Tumor necrosis factor-alpha inhibition protects against endotoxininduced endothelial glycocalyx perturbation. Atherosclerosis 2008;202:296-303

36. Vink H, Constantinescu AA, Spaan JA. Oxidized lipoproteins degrade the endothelial surface layer: implications for platelet-endothelial cell adhesion. Circulation 2000;101: 1500-1502

37. van den Berg BM, Vink H, Spaan JA. The endothelial glycocalyx protects against myocardial edema. Circ Res 2003; 92:592-594

38. Esmon CT. Role of coagulation inhibitors in inflammation. Thromb Haemost 2001;86:51-56

39. Levi M, de Jonge E, van der Poll T. Rationale for restoration of physiological anticoagulant pathways in patients with sepsis and disseminated intravascular coagulation. Crit Care Med 2001;29:S90-S94
40. Mesters RM, Mannucci PM, Coppola R, Keller T, Ostermann H, Kienast J. Factor VIIa and antithrombin III activity during severe sepsis and septic shock in neutropenic patients. Blood 1996;88:881-886

41. Bernard GR, Vincent JL, Laterre PF, et al. Efficacy and safety of recombinant human activated protein $\mathrm{C}$ for severe sepsis. N Engl J Med 2001;344:699-709

42. Levi $M$, ten Cate $H$, van der Poll $T$. Disseminated intravascular coagulation: state of the art. Thromb Haemost 1999;82:695-705

43. Warren BL, Eid A, Singer P, et al. Caring for the critically ill patient. High-dose antithrombin III in severe sepsis: a randomized controlled trial. JAMA 2001;286: 1869-1878

44. Blauhut B, Kramar H, Vinazzer H, Bergmann H. Substitution of antithrombin III in shock and DIC: a randomized study. Thromb Res 1985;39:81-89

45. Bishop JR, Schuksz M, Esko JD. Heparan sulphate proteoglycans fine-tune mammalian physiology. Nature 2007;446: 1030-1037

46. Baranska-Rybak W, Sonesson A, Nowicki R, Schmidtchen A. Glycosaminoglycans inhibit the antibacterial activity of LL-37 in biological fluids. J Antimicrob Chemother 2006;57: 260-265

47. Parish CR. The role of heparan sulphate in inflammation. Nat Rev Immunol 2006;6:633-643

48. Gotte M. Syndecans in inflammation. FASEB J 2003;17:575591

49. Lindahl U. Heparan sulfate-protein interactions-a concept for drug design? Thromb Haemost 2007;98:109-115

50. Xie X, Rivier AS, Zakrzewicz A, et al. Inhibition of selectinmediated cell adhesion and prevention of acute inflammation by nonanticoagulant sulfated saccharides. Studies with carboxyl-reduced and sulfated heparin and with trestatin a sulfate. J Biol Chem 2000;275:34818-34825

51. Levi M. Antithrombin in sepsis revisited. Crit Care 2005; 9:624-625

52. Bernard GR, Ely EW, Wright TJ, et al. Safety and dose relationship of recombinant human activated protein $\mathrm{C}$ for coagulopathy in severe sepsis. Crit Care Med 2001;29:20512059

53. Taylor FBJ, Toh CH, Hoots WK, Wada H, Levi M. Towards definition, clinical and laboratory criteria, and a scoring system for disseminated intravascular coagulation. Thromb Haemost 2001;86:1327-1330

54. Dhainaut JF, Yan SB, Joyce DE, et al. Treatment effects of drotrecogin alfa (activated) in patients with severe sepsis with or without overt disseminated intravascular coagulation. J Thromb Haemost 2004;2:1924-1933 